\title{
Effect of Sonication Output Power on the Crystal Structure and Magnetism of $\mathrm{SrFe}_{12} \mathrm{O}_{19}$ Nanoparticles
}

\author{
Roberto L. Palomino Resendiz ${ }^{1}$, Félix Sánchez De Jesús ${ }^{1}$, Claudia A. Cortés Escobedo ${ }^{2}$, \\ Leticia E. Hernández Cruz ${ }^{1}$ and Ana M. Bolarín Miró ${ }^{1, *}$ \\ 1 Área Académica de Ciencias de la Tierra y Materiales, Universidad Autónoma del Estado de Hidalgo, \\ Carretera Pachuca-Tulancingo Km. 4.5, Pachuca C.P. 42184 Hidalgo, Mexico; rlpr0288@gmail.com (R.L.P.R.); \\ fsanchez@uaeh.edu.mx (F.S.D.J.); hcruz@uaeh.edu.mx (L.E.H.C.) \\ 2 Centro de Investigación e Innovación Tecnológica del Instituto Politécnico Nacional, Cerrada Cecati s/n, \\ Col. Sta. Catarina, Azcapotzalco C.P. 02250, Ciudad de México, Mexico; claudia.alicia.cortes@gmail.com \\ * Correspondence: anabolarin@msn.com; Tel.: +52-77-1717-2000 (ext. 2280)
}

Received: 24 November 2017; Accepted: 16 January 2018; Published: 19 January 2018

\begin{abstract}
We reported the effect of the sonication output power (SOP), from 120, 180, to $240 \mathrm{~W}$, on the crystal structure, morphology, and magnetic properties of $\mathrm{SrFe}_{12} \mathrm{O}_{19}$ nanoparticles synthesized by sonochemical process assisted with heat treatment. X-ray Diffraction analysis of the obtained powder showed the formation of $\mathrm{Fe}_{3} \mathrm{O}_{4}$ with low crystallinity degree, which increased with the increase in SOP, together in a crystalline phase identified as $\mathrm{SrCO}_{3}$. The formation of $\mathrm{SrFe}_{12} \mathrm{O}_{19}$ started at $1073 \mathrm{~K}$, and was completed at $1173 \mathrm{~K}$. However, hexaferrite was obtained with the secondary phases $\alpha-\mathrm{Fe}_{2} \mathrm{O}_{3}$ and $\mathrm{SrFeO}_{2.5}$. At $1323 \mathrm{~K}$, the secondary phases vanished, and a single phase $\mathrm{SrFe}_{12} \mathrm{O}_{19}$ was detected. Vibrating Sample Magnetometry analysis showed that the $\mathrm{SrFeO}_{2.5}$ phase caused the formation of a hysteresis loop known as the Perminvar magnetic hysteresis loop. At $1323 \mathrm{~K}$, the powder synthesized at $120 \mathrm{~W}$ showed a specific magnetization of $67.15 \mathrm{Am}^{2} / \mathrm{kg}$ at $1.43 \times 10^{6} \mathrm{~A} / \mathrm{m}$, and coercivity of $4.69 \times 10^{4} \mathrm{~A} / \mathrm{m}$, with a spherical-like morphology and average particle size of $56.81 \mathrm{~nm}$ obtained by Scanning Electron Microscopy analysis. The increment of SOP promoted a high degree of crystallinity and decrease in crystal size. Additionally, it promoted the formation of secondary phases, induced agglomeration, and modified the morphology of the particles.
\end{abstract}

Keywords: strontium hexaferrite; $\mathrm{SrFe}_{12} \mathrm{O}_{19}$; sonochemical synthesis; sonication output power; magnetic nanoparticles; sonochemistry

\section{Introduction}

In recent years, the synthesis of magnetic nanomaterials has been investigated for various applications due to their unique magnetic properties [1]. The hexagonal ferrite type-M is denoted by the formula $\mathrm{MFe}_{12} \mathrm{O}_{19}$, where $\mathrm{M}$ is a divalent metal ion, typically $\mathrm{Sr}^{2+}, \mathrm{Ba}^{2+}$, or $\mathrm{Pb}^{2+}$ [2]. Since its discovery in 1950 [3], the hexagonal ferrite type- $\mathrm{M} \mathrm{SrFe}_{12} \mathrm{O}_{19}$ has played an important role in hard magnetic materials and has been studied for decades due to its good chemical stability, ferrimagnetic behavior, high Curie temperature, high saturation magnetization, high coercivity, high magneto-crystalline anisotropy (MCA), and it is inexpensive compared to similar compounds [4-6]. As it has magnetization values of about $60 \mathrm{Am}^{2} / \mathrm{kg}$ and coercivity of $4.37 \times 10^{5} \mathrm{~A} / \mathrm{m}$, it is widely used in magnetic recording material, data storage devices [7], magneto-optical recordings, microwave devices [8], permanent magnets, and electromagnetic devices [9]. A number of recent studies have considered $\mathrm{SrFe}_{12} \mathrm{O}_{19}$ nanoparticles (NPs) in a composite as a promising candidate material for biomedical applications, primarily because of their biocompatibility, an example of which is the treatment for cancer known as magnetic hyperthermia, where heat generated by magnetic nanoparticles in a radio frequency magnetic field is used to destroy malignant cells [10]. 
The structure of the ferrite type-M is formed by sequentially stacking the blocks of a cubic block $\mathrm{S}$, with a spinel-type structure, and a hexagonal block $R$, that form $S R S^{*} R^{*}$, where * denotes a $180^{\circ}$ rotation about the $c$ axis. The unit cell of $\mathrm{Sr}-\mathrm{M}$ contains two molecules $\mathrm{SrFe}_{12} \mathrm{O}_{19}(\mathrm{Z}=2)$ [1]. The structure comprises an $\mathrm{S}$ block, which is a spinel type structure denoted by the formula $\mathrm{AB}_{2} \mathrm{O}_{4}$ where the metal $\mathrm{A}^{2+}$ occupies tetrahedral interstitial sites, while the metal $\mathrm{B}^{3+}$ occupies octahedral interstitial sites [11], and a block $\mathrm{R}$ hexagonal type that contains the $\mathrm{Sr}^{2+}$ [2]. The hexagonal Sr-ferrite has a 24 magnetic $\mathrm{Fe}^{3+}$ ion per unit cell [12], which are distributed on five different crystallographic sites: three octahedral sites, $12 \mathrm{k}, 2 \mathrm{a}$ and $4 \mathrm{f}_{2}$, one tetrahedral site $4 \mathrm{f}_{1}$, and one trigonal bi-pyramidal site, $2 \mathrm{~b}$. Twelve $\mathrm{Fe}^{3+}$ ions have a chemical function, four of them have a spin in the downward direction at $4 \mathrm{f}_{1}\left(2 \mathrm{Fe}^{3+}\right)$ and $4 \mathrm{f}_{2}\left(2 \mathrm{Fe}^{3+}\right)$, and the eight $\mathrm{Fe}^{3+}$ ions have spin in the upward direction at $12 \mathrm{k}\left(6 \mathrm{Fe}^{3+}\right), 2 \mathrm{a}\left(1 \mathrm{Fe}^{3+}\right)$, and $2 \mathrm{~b}\left(1 \mathrm{Fe}^{3+}\right)$, according to the magnetic structure given by Gorter [13].

$\mathrm{SrFe}_{12} \mathrm{O}_{19}$ has been synthesized by several methods such as co-precipitation [14], mechanosynthesis [7], the hydrothermal process [5], and the sol-gel method [15] among others. However, these methods have a high cost, in addition, they are processes that are difficult to control and are tedious.

The use of ultrasonic irradiation for the synthesis of ferrites has been a research topic of great interest in recent years since it has high potential to produce nanocrystalline structures or nanoparticles [16]. Additionally, this synthesis method is friendly to the environment by using water as a solvent, and is also simpler and cheaper when compared to other synthetic routes [17]. Recently, we reported the synthesis of $\mathrm{SrFe}_{12} \mathrm{O}_{19}$ nanoparticles using the sonochemical assisted method, where the synthesis mechanism was described for particular experimental conditions [18]. Based on this study, the aim of this work was to extend knowledge on the synthesis mechanism and propose the best process parameters, particularly the sonication output power. In the process of sonochemistry, the molecules undergo a chemical reaction due to the application of ultrasound shockwaves with a combination of sinusoidal pressure waves at a frequency of $20 \mathrm{kHz}$ [16-20]. Due to the effect of this ultrasonic irradiation, sonochemistry induces the phenomenon of acoustic cavitation (the formation, growth, and violent collapse of bubbles in a liquid medium). When the transient bubble collapses, localized points known as Hot Spots are formed, where extreme conditions of temperature $(5000 \mathrm{~K})$ and pressure $(1800 \mathrm{kPa})$ are generated with a duration of nanoseconds within the bubbles [11]. According to some authors $[18,19]$ the sonication of an aqueous medium produces the process known as sonolysis, which is the breakage of the homolytic bond of the present water molecules, generating $\mathrm{H} \cdot$ and $\cdot \mathrm{OH}$ radicals, where these $\cdot \mathrm{OH}$ radicals recombine to form the strong oxidizer $\mathrm{H}_{2} \mathrm{O}_{2}$, which causes chemical and physical effects, as indicated in the following equations [17].

$$
\begin{gathered}
\mathrm{H}_{2} \mathrm{O} \stackrel{))}{\rightarrow} \mathrm{HO} \cdot+\mathrm{H} \\
\mathrm{H} \cdot+\mathrm{H} \cdot \rightarrow \mathrm{H}_{2} \\
\mathrm{OH}+\cdot \mathrm{OH} \rightarrow \mathrm{H}_{2} \mathrm{O}_{2} \\
\mathrm{Fe}^{2+}+\mathrm{H}_{2} \mathrm{O}_{2} \rightarrow \mathrm{Fe}^{3+}+\cdot 2 \mathrm{OH}
\end{gathered}
$$

Using ultrasonic waves in media with high viscosity leads to an effect of acceleration of the dynamics and rate of chemical reactions, improving the activity of the solid particle surface and the dynamic of the reaction, which induces an acceleration in the mass transfer process. By controlling parameters such as the sonication output power, different end-product properties can be obtained such as particle size, crystallinity, magnetic properties, morphology, etc. Unfortunately, there are very few studies in the published literature that describe in an understandable way the effects of the variation of the sonication output power (SOP) on the above-mentioned properties of the obtained end-product.

Kandjani et al. [16] and Hassanjani-Roshan et al. [19] reported on similar studies about the effects of SOP variation on the sonochemical synthesis of nanoparticles of $\mathrm{ZnO}$ and $\alpha-\mathrm{Fe}_{2} \mathrm{O}_{3}$, respectively. Their results only described the effects on the crystal structure and morphology of the particles 
obtained at low SOP (1-45 W). Additionally, they did not report on the study of the magnetic properties; therefore, the effect of the SOP variation on the crystalline structure and its ratio with the magnetic properties of the obtained material are not well understood. The technological and biomedical applications of transition metal oxide nanoparticles are attributed to their unique characteristics, such as a large surface area, confinement of the quantum effect, optical and magnetic properties, etc. In recent studies, Kaviyarasu et al. $[20,21]$ reported the synthesis of $\mathrm{ZnO}$ nanoparticles, for use in photocatalysis, antibacterial applications, and to reduce the cytotoxicity in a biological system of $\mathrm{ZnO}$ doped with $\mathrm{TiO}_{2}$.

The aim of this study was to investigate the effect of SOP applied in the synthesis of nanoparticles of strontium hexaferrite by a sonochemical assisted method using iron and strontium metallic acetates as precursor materials in a diethylene glycol solution and deionized water. To evaluate the effect of varying SOP and to compare with other authors [16,19], we used high SOP $(120,180$, and $240 \mathrm{~W})$. These values were chosen in the first instance as the maximum power available of the sonication device used was $300 \mathrm{~W}$, therefore, the chosen values corresponded to $40 \%, 60 \%$, and $80 \%$ of the maximum power of the device. In the second instance, it is well known that SOPs above $100 \mathrm{~W}$ are considered high sonication powers, and similar studies up until now have used SOPs below this value, for which it is expected that there are significant effects on the properties of the materials obtained. The effect of this high SOP on the complex crystal structure of the strontium hexaferrite, the morphology, and its influence on magnetic properties is discussed.

\section{Materials and Methods}

The sonochemical synthesis was performed using iron acetate (II) (anhydride, Fe 29.5\% min, Alfa Aesar, Haverhill, MA, USA) and strontium acetate (99.995\% purity, Sigma Aldrich, St. Louis, $\mathrm{MO}, \mathrm{USA}$ ) as precursors. Stoichiometric amounts of these materials were dissolved in $50 \mathrm{~mL}$ of solvent, a mixture of diethylene glycol (99\%, Alfa Aesar, Haverhill, MA, USA) and deionized water $(10 \% v / v)$ in a ratio of $2: 1$, for $1 \mathrm{~h}$ under mechanical stirring in an air atmosphere, following the reactions corresponding to obtaining strontium hexaferrite.

$$
12 \mathrm{Fe}\left(\mathrm{C}_{2} \mathrm{H}_{3} \mathrm{O}_{2}\right)_{2}+\mathrm{Sr}\left(\mathrm{C}_{2} \mathrm{H}_{3} \mathrm{O}_{2}\right)_{2}+13 \mathrm{H}_{2} \mathrm{O} \stackrel{))), \text { DEG: } \mathrm{H}_{2} \mathrm{O}}{\longrightarrow} \mathrm{SrFe}_{12} \mathrm{O}_{19}+26\left(\mathrm{C}_{2} \mathrm{H}_{4} \mathrm{O}_{2}\right)
$$

The solution was sonicated using an Ultrasonic Homogenizer 300VT equipped with a piezoelectric transducer at a frequency of $20 \mathrm{kHz}$ and a solid titanium tip of $9.5 \mathrm{~mm}$, which was immersed directly into the solution up to $1.42 \mathrm{~cm}$, in accordance with the operation manual of the device, which indicates that it must be submerged $1.5^{*}$ (diameter of the tip). The experiments were performed at 120,180 , and $240 \mathrm{~W}$ of SOP. The baker was placed into an ice bucket, where the temperature of the solution in all cases did not exceed $318 \mathrm{~K}$ after $3 \mathrm{~h}$ of ultrasonic irradiation. In addition, there were no changes to the sonicated volume. Figure 1 shows a schematic diagram of the experimental sonochemical set up. After the sonochemical process, powders were washed three times using ethanol, and centrifuged at $12,000 \mathrm{~m}^{-1}$ for $15 \mathrm{~min}$. Subsequently, the powders were dried at $353 \mathrm{~K}$ in air. The powders obtained (named "as obtained") were heat treated at temperatures of 1073, 1173, and $1323 \mathrm{~K}$ in air. 


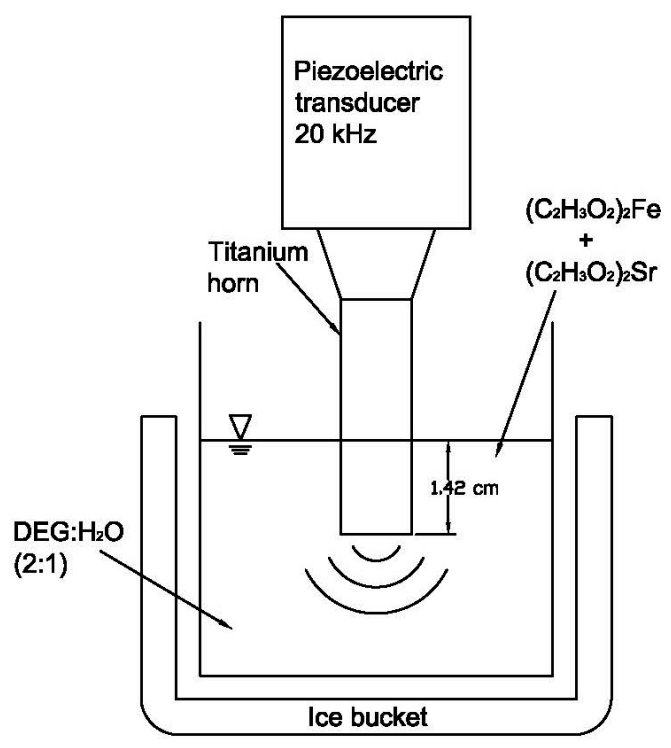

Figure 1. Schematic diagram of experimental sonochemical set up.

The analysis of the crystal structure by X-ray diffraction (XRD) of the obtained powders was performed in a Equinox 2000 diffractometer (Inel, Artenay, France), using radiation Co. $K_{\alpha 1}$ $(\lambda=1.7890100 \AA)$. Geometric symmetry sweep measurements were carried out from $20^{\circ}$ to $80^{\circ}$ in $2 \theta$. Rietveld refinements were achieved on the X-ray diffraction patterns to obtain the percentages of the different phases, crystallite size, and microstrain of the powders. This method considers all the collected information in a diffraction pattern and uses a least-squares approach to refine the theoretical line profile until it matches the measured profile [22]. Crystallographic data were obtained from the Crystallographic Open Database [23]. Morphological analysis and particle size determination were accomplished with scanning electron microscopy (SEM) JEOL-100-CX II (JEOL, Tokyo, Japan). Magnetization studies were performed at room temperature using a EV7 vibrating sample magnetometer (VSM, Microsense, Lowell, MA, USA) with a $\pm 1.43 \times 10^{6} \mathrm{~A} / \mathrm{m}$ field.

\section{Results}

\subsection{Crystal Structure}

Figure 2 shows the XRD patterns of powders synthesized by sonochemistry using different SOPs $(120,180$, and $240 \mathrm{~W}$ ) over $3 \mathrm{~h}$ without heat treatment (as obtained). At an SOP of $120 \mathrm{~W}$, it was observed that the powders consisted of a mixture of $\mathrm{Fe}_{3} \mathrm{O}_{4}$ (Powder Diffraction File (PDF)-2 00-065-3107), showing a low crystallinity degree, and $\mathrm{SrCO}_{3}$ (PDF-2 00-084-1778). Moreover, by increasing the SOP to $240 \mathrm{~W}$, the phases remained the same, but the powders obtained showed a higher crystallinity degree, as observed through the sharpening of diffraction peaks as the power was increased. This fact can be attributed to the effect of SOP on the nucleation rate and crystal growth as a consequence of the increase in the number and rate of reactions, which is typical of the sonochemistry process [24]. At a higher SOP, a greater number of Hot Spots were produced, therefore, there was a greater number of reaction sites, which reached the energy necessary to generate nuclei and crystallize, in this case, an $\mathrm{Fe}_{3} \mathrm{O}_{4}$ phase. 


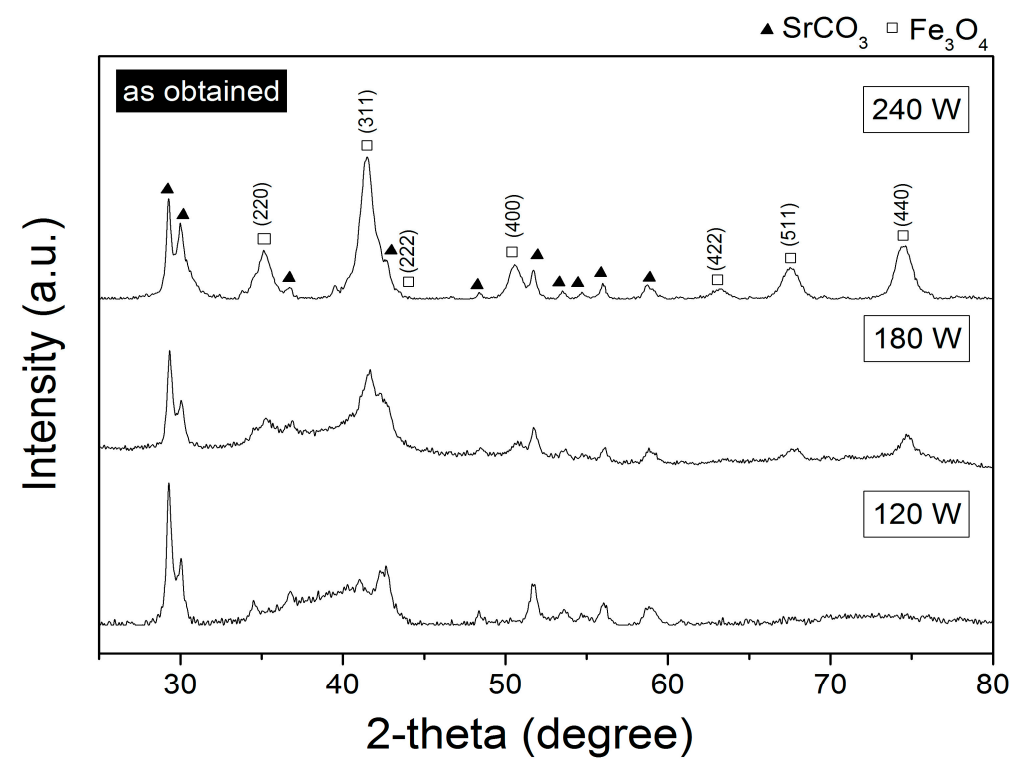

Figure 2. X-ray diffraction patterns of powders "as obtained" with sonication output power of 120, 180, and $240 \mathrm{~W}$ over $3 \mathrm{~h}$.

Table 1 shows phase vol (\%), crystallite size (D), and microstrain ( $\mu \mathrm{s})$ of the synthesized powders obtained by the Rietveld refinement of the XRD patterns in Figure 2. Additionally, it shows the crystallinity percentage index (\%), which was calculated according to the following expression proposed by Bailey et al. [25]: $I_{\mathrm{C}}(\%)=\left[1-I_{\mathrm{mi}} / I_{\mathrm{MA}}\right] \times 100$; where, $I_{\mathrm{c}}$ is the minimum intensity peak value, $I_{\mathrm{mi}}$ is the minimum intensity peak value, and $I_{\mathrm{MA}}$ is the maximum intensity peak value.

Table 1. Data from the Rietveld refinements of the X-ray diffraction patterns and index of crystallinity of the powders obtained at 120,180, and $240 \mathrm{~W}$ without heat treatment.

\begin{tabular}{ccccccc}
\hline Power & $\begin{array}{c}\text { Phases, Space } \\
\text { Group }\end{array}$ & $\begin{array}{c}\text { Crystallography Open } \\
\text { Database (COD) ID }\end{array}$ & vol \% & $\begin{array}{c}\text { Crystallite } \\
\text { Size (nm) }\end{array}$ & $\begin{array}{c}\text { Microstrain } \\
\text { (adim) }\end{array}$ & $\begin{array}{c}\text { Index of } \\
\text { Crystallinity (\%) }\end{array}$ \\
\hline \multirow{2}{*}{$\mathbf{1 2 0} \mathbf{~ W}$} & $\mathrm{Fe}_{3} \mathrm{O}_{4}, \mathrm{Fd}-3 m$ & 9005816 & $85.96 \pm 0.95$ & $12.4 \pm 1.4$ & 0.030024 & 24.13 \\
& $\mathrm{SrCO}_{3}, \mathrm{Pmcn}$ & 9008198 & $14.04 \pm 0.0$ & $318.6 \pm 7.7$ & 0.005322 & 92.54 \\
\hline \multirow{2}{*}{$\mathbf{1 8 0} \mathbf{W}$} & $\mathrm{Fe}_{3} \mathrm{O}_{4}, \mathrm{Fd}-3 m$ & 9005816 & $86.95 \pm 0.5$ & $6.9 \pm 1.8$ & 0.002524 & 63.99 \\
& $\mathrm{SrCO}_{3}, \mathrm{Pmcn}$ & 9008198 & $13.05 \pm 0.0$ & $211.8 \pm 1.0$ & 0.004980 & 85.08 \\
\hline \multirow{2}{*}{$\mathbf{2 4 0} \mathbf{~ W}$} & $\mathrm{Fe}_{3} \mathrm{O}_{4}, \mathrm{Fd}-3 m$ & 9005816 & $88.97 \pm 0.13$ & $5.7 \pm 0.8$ & 0.000049 & 95.08 \\
& $\mathrm{SrCO}_{3}, \mathrm{Pmcn}$ & 9008198 & $11.02 \pm 0.0$ & $115.3 \pm 1.8$ & 0.000499 & 65.50 \\
\hline
\end{tabular}

As can be observed in Table 1, the results indicate that $120 \mathrm{~W}$ promoted the formation of nuclei and initiated the growth of the crystals. However, the energy provided was not sufficient for synthesized crystalline hexaferrite, forming amorphous magnetite and strontium carbonate. Furthermore, at $180 \mathrm{~W}$ and $240 \mathrm{~W}$ of SOP, the energy was enough to form nuclei and increased the percentage of crystallization. Therefore, the increase in SOP increased the percentage in volume of the $\mathrm{Fe}_{3} \mathrm{O}_{4}$, while the percentage of $\mathrm{SrCO}_{3}$ decreased. In addition, at 180 and $240 \mathrm{~W}$, a high degree of crystallinity and decrease in the crystal size was promoted.

However, even when an increase in SOP produced a higher phase of $\mathrm{Fe}_{3} \mathrm{O}_{4}$ with a high degree of crystallinity, the sonochemical process did not provide sufficient energy for the synthesis of strontium hexaferrite. Therefore, it was necessary to add energy by means of a heat treatment to achieve the desired phase. Figures $3-5$ show the effect of an annealing temperature into the crystal structure of the sonicated powders. 


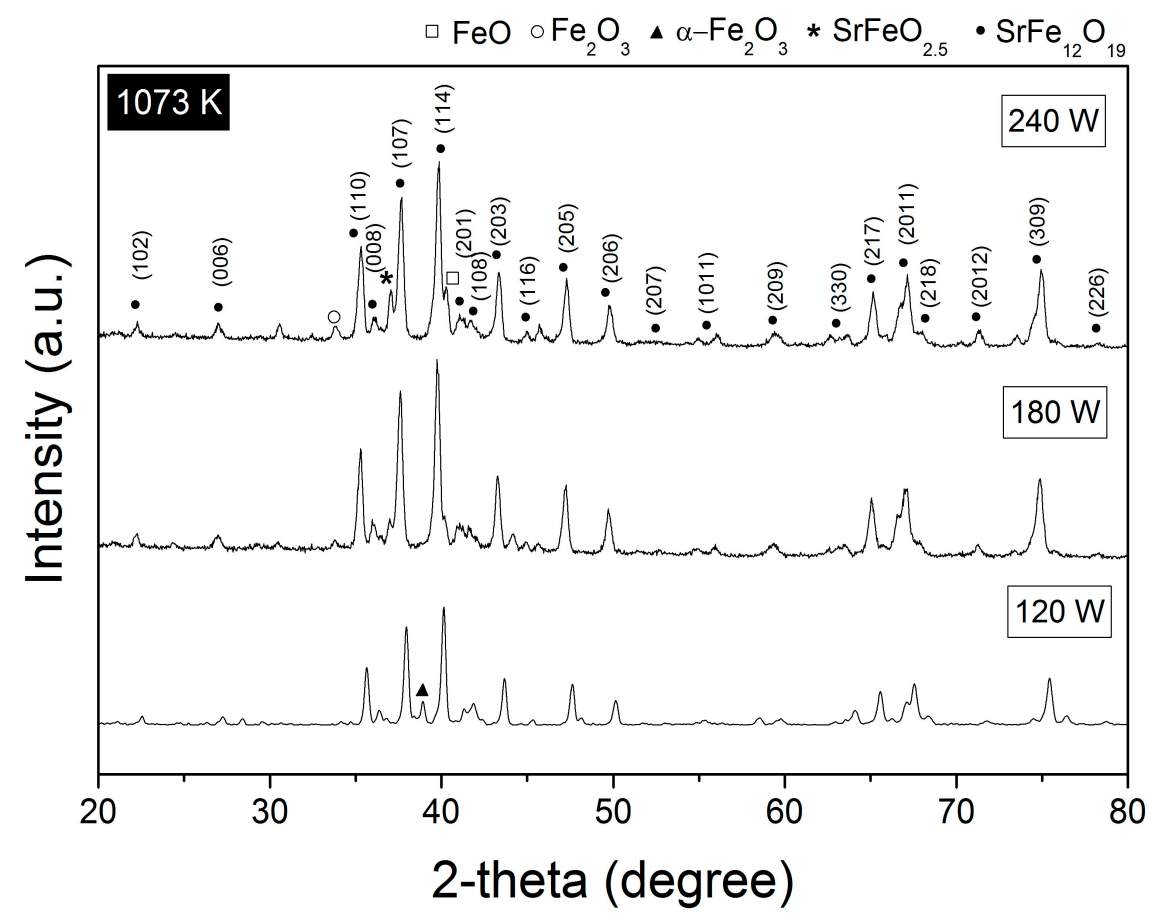

Figure 3. XRD patterns of powders after applying different sonication output power (SOP) for $3 \mathrm{~h}$ and thermal treatment at $1073 \mathrm{~K}$.

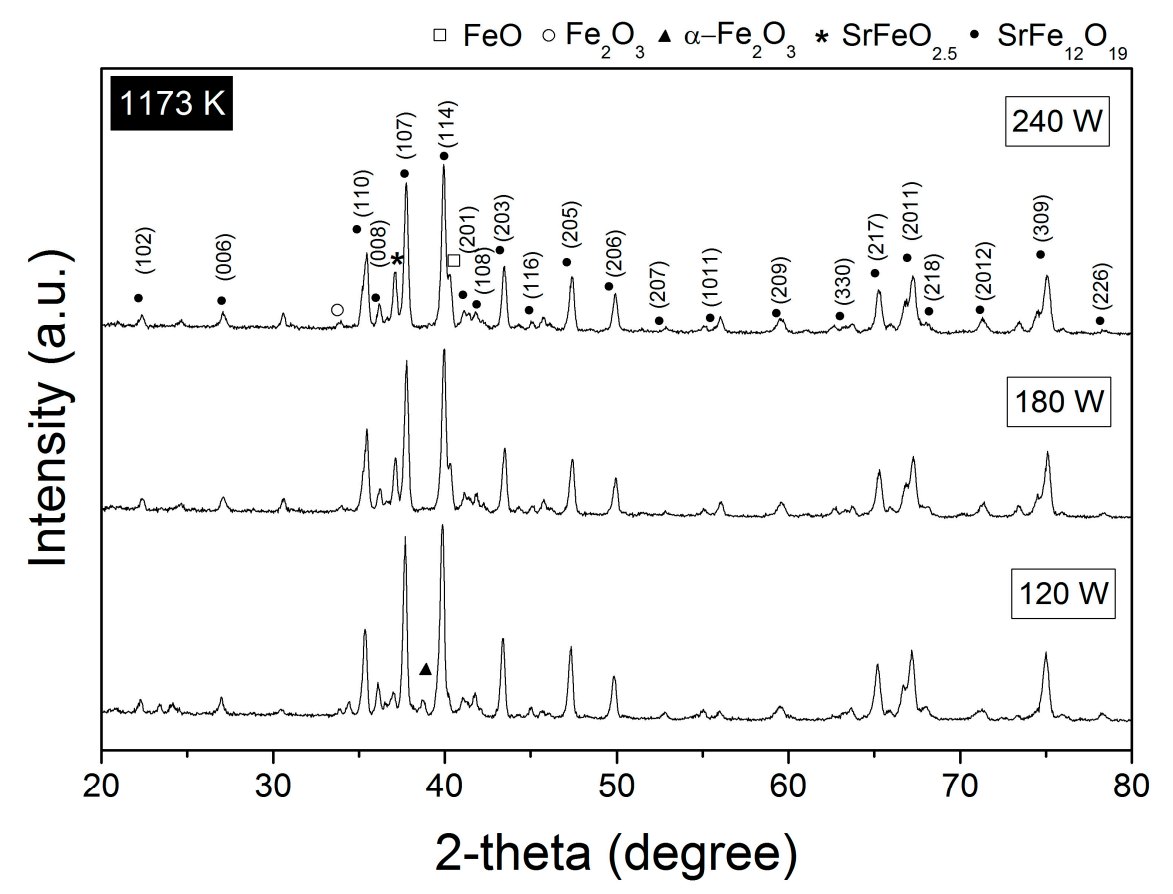

Figure 4. XRD patterns of powders after applying different SOP for $3 \mathrm{~h}$ and thermal treatment at $1173 \mathrm{~K}$. 


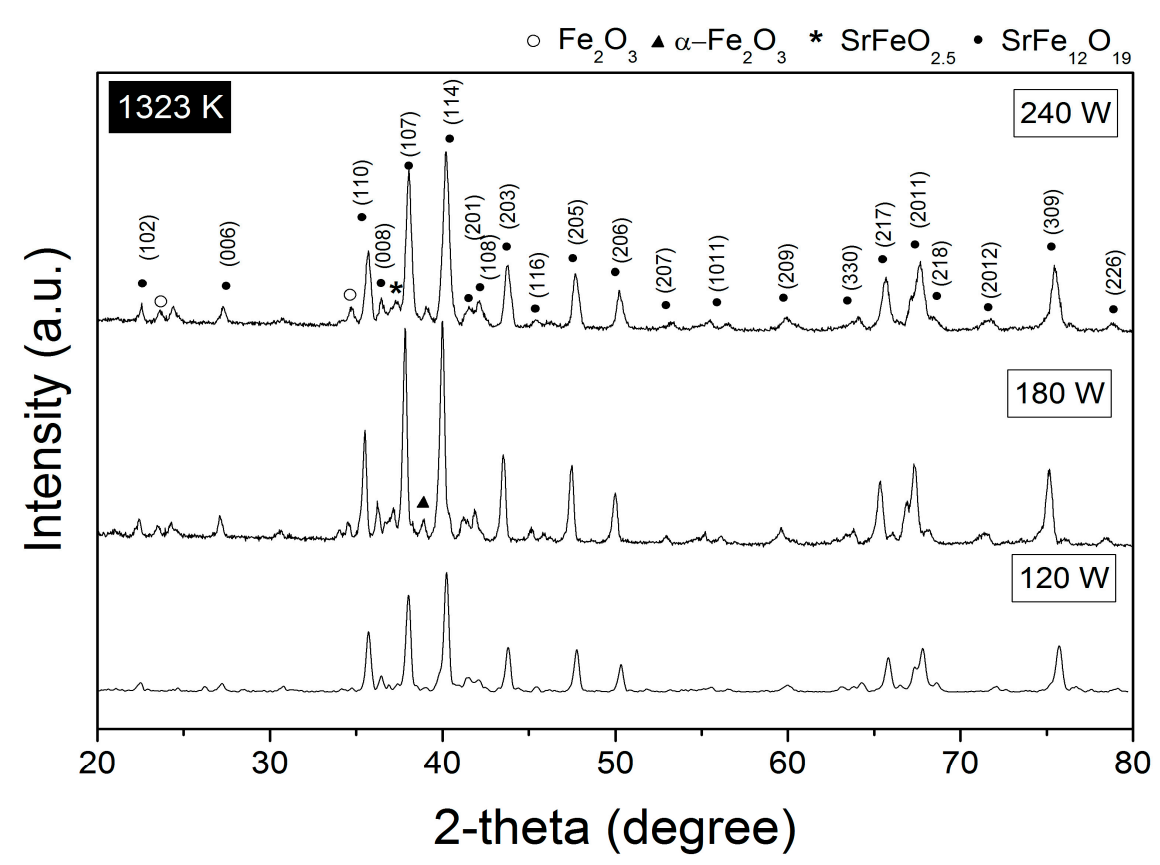

Figure 5. XRD patterns of powders after applying different SOP for $3 \mathrm{~h}$ and thermal treatedment at $1323 \mathrm{~K}$.

Figure 3 shows the XRD patterns corresponding to the effect of annealing at $1073 \mathrm{~K}$ on the powders obtained using different SOP. As can be seen, the XRD pattern of the powder synthesized using $120 \mathrm{~W}$ of SOP identified diffraction peaks that corresponded to $\mathrm{SrFe}_{12} \mathrm{O}_{19}$ (PDF-2 00-079-1411) and $\alpha-\mathrm{Fe}_{2} \mathrm{O}_{3}$ (PDF-2 01-084-0311). Additionally, in the XRD patterns of the powders synthesized using 180 and $240 \mathrm{~W}$ of SOP, peaks belonging to $\mathrm{SrFe}_{12} \mathrm{O}_{19}$ mixed with $\alpha-\mathrm{Fe}_{2} \mathrm{O}_{3}$ were observed. In addition, an interesting difference was found in these patterns (180 and $240 \mathrm{~W})$. The XRD patterns at $37.04^{\circ}$ of $2 \theta$ presented a peak that increased its intensity in proportion to the increase of SOP; this phase was identified as a cubic type Perovskite structure $\mathrm{SrFeO}_{2.5}$ (PDF-2 00-033-0677). This phase formed from the reaction between $\mathrm{SrCO}_{3}$ and $\alpha-\mathrm{Fe}_{2} \mathrm{O}_{3}$, which occurred at heat in a range from 1053 to $1173 \mathrm{~K}[5,26]$. Moreover, peaks at $23.57^{\circ}$ and $34.68^{\circ}$ of $2 \theta$ were identified as a polymorphic phase of hematite, $\mathrm{Fe}_{2} \mathrm{O}_{3}$ (PDF-2 00-021-0920) [27]. Additionally, an increase in the intensity of the diffraction peak at $40.34^{\circ}$ of $2 \theta$ was observed, which corresponded to FeO (PDF-2 00-049-1447). This phase was ascribed to the decomposition of $\mathrm{Fe}_{2} \mathrm{O}_{3}$ [28]. The presence of these secondary phases was attributed to the fact that the increase in SOP in the synthesis of the powders obtained at 180 and $240 \mathrm{~W}$ and the subsequent heat treatment at $1073 \mathrm{~K}$ produced an excess of the $\mathrm{Fe}^{3+}$ species that promotes the formation and crystallization of Sr-Fe oxides as contaminating phases in the powders.

The XDR for the "as obtained" powder annealed at $1173 \mathrm{~K}$ and $1323 \mathrm{~K}$ are shown in Figures 4 and 5, respectively. The results showed the same behavior as that of the powder annealed at $1073 \mathrm{~K}$, as previously described.

Table 2 shows the Rietveld refinement results of the phase vol \%, the crystallite size (D), and the microstrain $(\mu \mathrm{s})$ of the XRD patterns (Figures 3-5). These results confirmed that high SOPs such as 180 and $240 \mathrm{~W}$ promoted the crystallization of secondary phases such as $\mathrm{SrFeO}_{2.5}, \alpha-\mathrm{Fe}_{2} \mathrm{O}_{3}$, and $\mathrm{Fe}_{2} \mathrm{O}_{3}$, in annealed powders. Likewise, for the low annealing temperature of $1073 \mathrm{~K}$, the crystal size decreased considerably with the SOP, achieving $4.9 \mathrm{~nm}$ at $240 \mathrm{~W}$. In contrast, for the high annealing temperatures of $1173 \mathrm{~K}$ and $1323 \mathrm{~K}$, the crystal size increased with the SOP due to the fact that at high annealing temperature, the nucleation of the $\mathrm{SrFe}_{12} \mathrm{O}_{19}$ is completed and the growing stage promoted. Therefore, it can be concluded that the best condition of SOP is $120 \mathrm{~W}$, followed by annealing at $1323 \mathrm{~K}$. Under these experimental conditions, an almost pure phase of $\mathrm{SrFe}_{12} \mathrm{O}_{19}(98.8 \%)$ with a crystal size around $64 \mathrm{~nm}$ was obtained. Furthermore, the microstrain did not show a significant difference and remained constant for each SOP due to the thermal treatment releasing the microstains. 
Table 2. Data from the Rietveld refinements of the XRD patterns of the powders obtained at 120, 180, and $240 \mathrm{~W}$ with heat treatment at 1073,1173 , and $1323 \mathrm{~K}$.

\begin{tabular}{|c|c|c|c|c|c|}
\hline Power & Phases, Space Group & $\begin{array}{l}\text { Crystallography Open } \\
\text { Database (COD) ID }\end{array}$ & vol \% & $\begin{array}{l}\text { Crystallite } \\
\text { Size (nm) }\end{array}$ & $\begin{array}{l}\text { Microstrain } \\
\quad \text { (adim) }\end{array}$ \\
\hline \multicolumn{6}{|c|}{ Annealed at $1073 \mathrm{~K}$} \\
\hline \multirow{2}{*}{$120 \mathrm{~W}$} & $\mathrm{SrFe}_{12} \mathrm{O}_{19}, P 63 / m m c$ & 1006000 & $90.34 \pm 0.0$ & $81.7 \pm 2.2$ & 0.000958 \\
\hline & $\alpha-\mathrm{Fe}_{2} \mathrm{O}_{3}, R-3 c$ & 9015065 & $9.66 \pm 0.64$ & $7.1 \pm 0.6$ & 0.000304 \\
\hline \multirow{3}{*}{$180 \mathrm{~W}$} & $\mathrm{SrFe}_{12} \mathrm{O}_{19}, P 63 / m m c$ & 1006000 & $96.78 \pm 1.1$ & $61.09 \pm 1.3$ & 0.001088 \\
\hline & $\alpha-\mathrm{Fe}_{2} \mathrm{O}_{3}, R-3 c$ & 9015065 & $1.24 \pm 0.02$ & $9.6 \pm 1.2$ & 0.006622 \\
\hline & $\mathrm{SrFeO}_{2.5}, P m-3 m$ & 1502549 & $1.98 \pm 2.1$ & $9.9 \pm 0.1$ & 0.000603 \\
\hline \multirow{5}{*}{$240 \mathrm{~W}$} & $\mathrm{SrFe}_{12} \mathrm{O}_{19}, P 63 / m m c$ & 1006000 & $95.58 \pm 0.71$ & $55.1 \pm 1.7$ & 0.001013 \\
\hline & $\alpha-\mathrm{Fe}_{2} \mathrm{O}_{3}, R-3 c$ & 9015065 & $1.54 \pm 0.41$ & $5.4 \pm 0.7$ & 0.001219 \\
\hline & $\mathrm{SrFeO}_{2.5}, P m-3 m$ & 1502549 & $2.41 \pm 0.0$ & $4.9 \pm 0.63$ & 0.000501 \\
\hline & $\mathrm{Fe}_{2} \mathrm{O}_{3}, R-3 c$ & 1011240 & $0.30 \pm 0.6$ & $9.7 \pm 1.8$ & 0.002212 \\
\hline & $\mathrm{FeO}, \mathrm{Pm}-3 m$ & 2106936 & $0.17 \pm 0.47$ & $4.2 \pm 0.15$ & 0.001980 \\
\hline \multicolumn{6}{|c|}{ Annealed at $1173 \mathrm{~K}$} \\
\hline \multirow{3}{*}{$120 \mathrm{~W}$} & $\mathrm{SrFe}_{12} \mathrm{O}_{19}, P 63 / m m c$ & 1006000 & $97.24 \pm 0.0$ & $67.9 \pm 1.7$ & 0.000945 \\
\hline & $\alpha-\mathrm{Fe}_{2} \mathrm{O}_{3}, R-3 c$ & 9015065 & $2.24 \pm 0.04$ & $9.4 \pm 0.45$ & 0.001205 \\
\hline & $\mathrm{SrFeO}_{2.5}, \mathrm{Pm}-3 m$ & 1502549 & $0.52 \pm 0.19$ & $11.7 \pm 1.6$ & 0.002191 \\
\hline \multirow{3}{*}{$180 \mathrm{~W}$} & $\mathrm{SrFe}_{12} \mathrm{O}_{19}, P 63 / m m c$ & 1006000 & $95.11 \pm 0.5$ & $75.5 \pm 2.3$ & 0.000839 \\
\hline & $\alpha-\mathrm{Fe}_{2} \mathrm{O}_{3}, R-3 c$ & 9015065 & $1.22 \pm 0.01$ & $8.9 \pm 0.49$ & 0.002454 \\
\hline & $\mathrm{SrFeO}_{2.5}, P m-3 m$ & 1502549 & $3.67 \pm 0.59$ & $9.9 \pm 0.26$ & 0.001775 \\
\hline \multirow{5}{*}{$240 \mathrm{~W}$} & $\mathrm{SrFe}_{12} \mathrm{O}_{19}, P 63 / m m c$ & 1006000 & $92.75 \pm 0.0$ & $77.2 \pm 4.1$ & 0.000838 \\
\hline & $\alpha-\mathrm{Fe}_{2} \mathrm{O}_{3}, R-3 c$ & 9015065 & $1.23 \pm 0.04$ & $3.3 \pm 0.80$ & 0.001243 \\
\hline & $\mathrm{SrFeO}_{2.5}, \mathrm{Pm}-3 m$ & 1502549 & $4.10 \pm 0.30$ & $8.7 \pm 0.31$ & 0.001365 \\
\hline & $\mathrm{Fe}_{2} \mathrm{O}_{3}, R-3 c$ & 1011240 & $0.65 \pm 0.5$ & $4.7 \pm 0.17$ & 0.002753 \\
\hline & $\mathrm{FeO}, P m-3 m$ & 2106936 & $0.25 \pm 0.2$ & $10 \pm 0.9$ & 0.023388 \\
\hline \multicolumn{6}{|c|}{ Annealed at $1323 \mathrm{~K}$} \\
\hline \multirow{2}{*}{$120 \mathrm{~W}$} & $\mathrm{SrFe}_{12} \mathrm{O}_{19}, P 63 / m m c$ & 1006000 & $98.8 \pm 1.95$ & $63.4 \pm 1.58$ & 0.000922 \\
\hline & $\alpha-\mathrm{Fe}_{2} \mathrm{O}_{3}, R-3 c$ & 9015065 & $1.2 \pm 0.02$ & $9.9 \pm 0.15$ & 0.011751 \\
\hline \multirow{3}{*}{$180 \mathrm{~W}$} & $\mathrm{SrFe}_{12} \mathrm{O}_{19}, P 63 / m m c$ & 1006000 & $91.92 \pm 1.47$ & $73.3 \pm 1.29$ & 0.001342 \\
\hline & $\alpha-\mathrm{Fe}_{2} \mathrm{O}_{3}, R-3 c$ & 9015065 & $7.60 \pm 0.02$ & $10.1 \pm 0.26$ & 0.010153 \\
\hline & $\mathrm{SrFeO}_{2.5}, \mathrm{Pm}-3 \mathrm{~m}$ & 1502549 & $0.48 \pm 0.27$ & $10.0 \pm 0.11$ & 0.000604 \\
\hline \multirow{2}{*}{$240 \mathrm{~W}$} & $\mathrm{SrFe}_{12} \mathrm{O}_{19}, P 63 / m m c$ & 1006000 & $96.62 \pm 9.42$ & $84.7 \pm 1.35$ & 0.001013 \\
\hline & $\mathrm{Fe}_{2} \mathrm{O}_{3}, R-3 c$ & 1011240 & $3.38 \pm 0.34$ & $9.8 \pm 0.26$ & 0.000409 \\
\hline
\end{tabular}

\subsection{Morphology Analysis}

To qualitatively determine the effect of increasing SOP on particle size and morphology of the heat treated powders, representative SEM micrographs (Figure 6) of the powders synthesized sonochemically by 120,180 , and $240 \mathrm{~W}$ of SOP with heat treatment at $1323 \mathrm{~K}$ are shown. As observed, the powders consisted in agglomerates of particles with rounded morphology, which formed a bigger particle. It can be further noted that the variation of SOP applied in the synthesis had an effect on their morphology and size. The powder obtained at $120 \mathrm{~W}$ qualitatively showed the lowest agglomerate size, and the greatest homogeneity in morphology and size. To quantitatively determine the average particle size of this powder, an image analysis was undertaken (the equivalent spherical projected area diameter was calculated by setting the projected area equal to the equivalent area of a circle), thereby obtaining the nanoparticle size distribution presented in the histogram (Figure 6b), where an average particle size diameter was estimated as $56.81 \mathrm{~nm}$. 

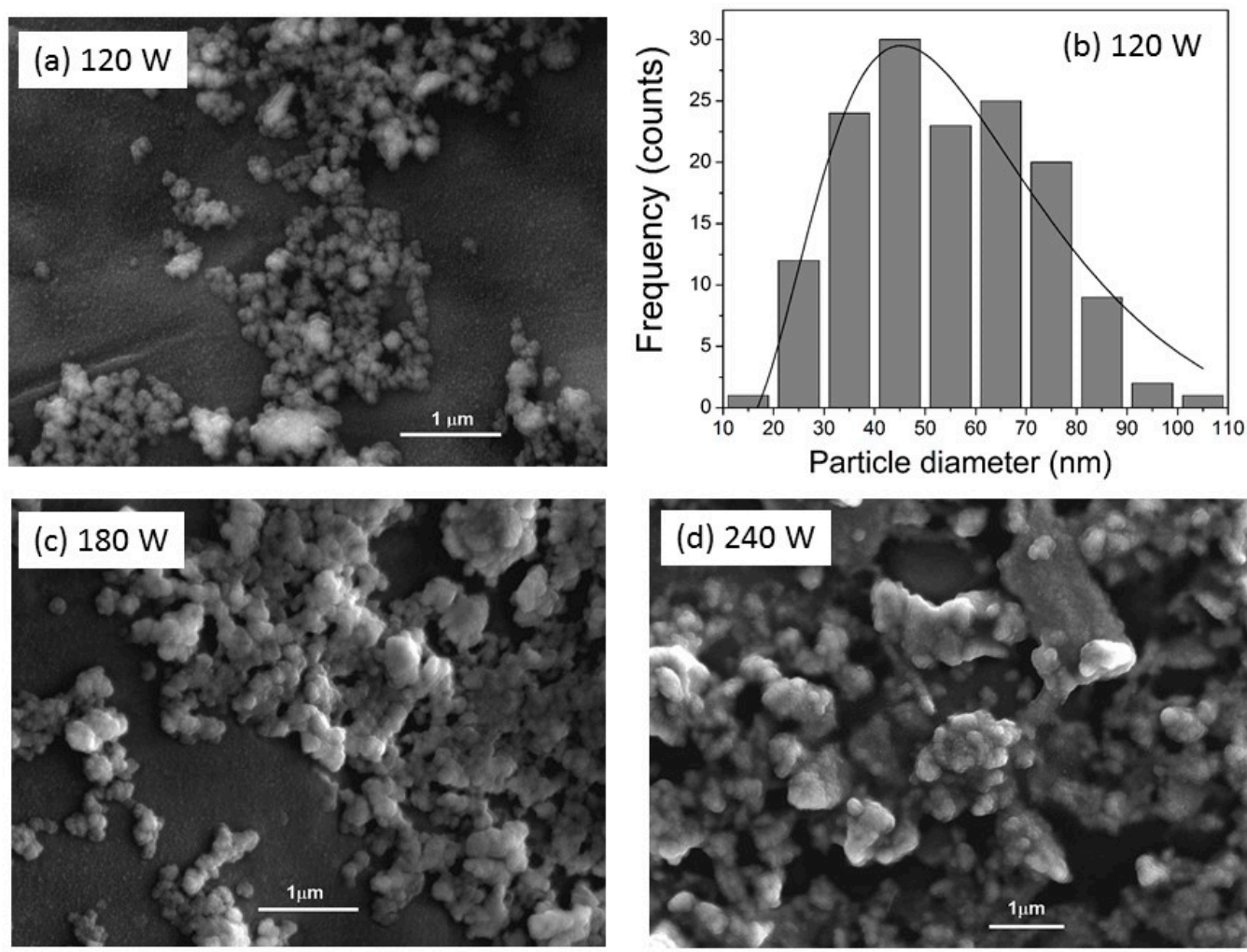

Figure 6. Micrographs of powders "as obtained" synthesized at different SOP values: (a) $120 \mathrm{~W}$; (b) Histogram of particle size distribution of the powder obtained at $120 \mathrm{~W}$; (c) $180 \mathrm{~W}$; and (d) $240 \mathrm{~W}$.

As observed in Figure 6, the nanoparticles obtained with $120 \mathrm{~W}$ (Figure 6a) of SOP had a spherical-like morphology, commonly produced by the sonochemical synthesis process $[16,18,21]$. On the other hand, by increasing the SOP at $180 \mathrm{~W}$ (Figure 6c), agglomerates of particles were observed, which acquired a quasi-rounded morphology. Finally, in Figure 6d, the powder obtained at $240 \mathrm{~W}$ was formed by large agglomerates and particles in bulk with an undefined morphology. It was expected that for higher levels of SOP (180 and $240 \mathrm{~W})$, the particles obtained would show a greater homogeneity in their morphology and sizes; however, the results presented in Figure 6 indicate the opposite, where the effect of high levels SOP promoted an agglomeration of the obtained particles and a modification in its morphology independently of the thermal treatment, as the results shown belong to the thermal treatment at the same temperature $(1323 \mathrm{~K})$.

\subsection{Magnetic Properties}

Figure 7 shows the hysteresis loops $\mathrm{M}(\mathrm{H})$ of the powders obtained by sonochemistry with different levels of SOP $(120,180,240 \mathrm{~W})$ with heat treatment at 1073, 1173, and $1323 \mathrm{~K}$. For the as obtained powder, at $120 \mathrm{~W}$ (Figure 7a) the material showed weak magnetic behavior (line with positive slope) with a specific magnetization of $2.2 \mathrm{Am}^{2} / \mathrm{kg}$ at $1.43 \times 10^{6} \mathrm{~A} / \mathrm{m}$. In the same figure, it can be observed that at $180 \mathrm{~W}$, the specific magnetization increased to $12.4 \mathrm{Am}^{2} / \mathrm{kg}$ at $1.43 \times 10^{6} \mathrm{~A} / \mathrm{m}$; moreover, the shape of the curve obtained was typical of the ferrimagnetic behavior of $\mathrm{Fe}_{3} \mathrm{O}_{4}$. Finally, in the powder synthesized with $240 \mathrm{~W}$, a significant increase in their specific magnetization $\left(39.5 \mathrm{Am}^{2} / \mathrm{kg}\right.$ at $1.43 \times 10^{6} \mathrm{~A} / \mathrm{m}$ ) was observed. The increase in the specific magnetization, as well as the change in the curve shape of the powders obtained at 120 and $180 \mathrm{~W}$, was attributed to two main factors: the increases in the degree of crystallinity and the decrease of the crystallite size of the $\mathrm{Fe}_{3} \mathrm{O}_{4}$ by the increase in SOP, even when the mass percentage of this phase is similar for all cases. Therefore, there was an improvement in the homogeneity of $\mathrm{Fe}_{3} \mathrm{O}_{4}$ that increased the magnetic dominance of the particles, resulting in the alignment of the magnetic spins along the direction of the applied field. 
Another important factor was the contribution of nonmagnetic compound $\mathrm{SrCO}_{3}$. Due to the increase in SOP, the percentage in mass of this phase decreased as well as its degree of crystallinity, and its presence is reflected in the values of specific magnetization of $\mathrm{Fe}_{3} \mathrm{O}_{4}$. This was observed even with the increase of degree of crystallization in the $\mathrm{Fe}_{3} \mathrm{O}_{4}$ phase, where the values of specific magnetization were lower than those reported for this type of material.
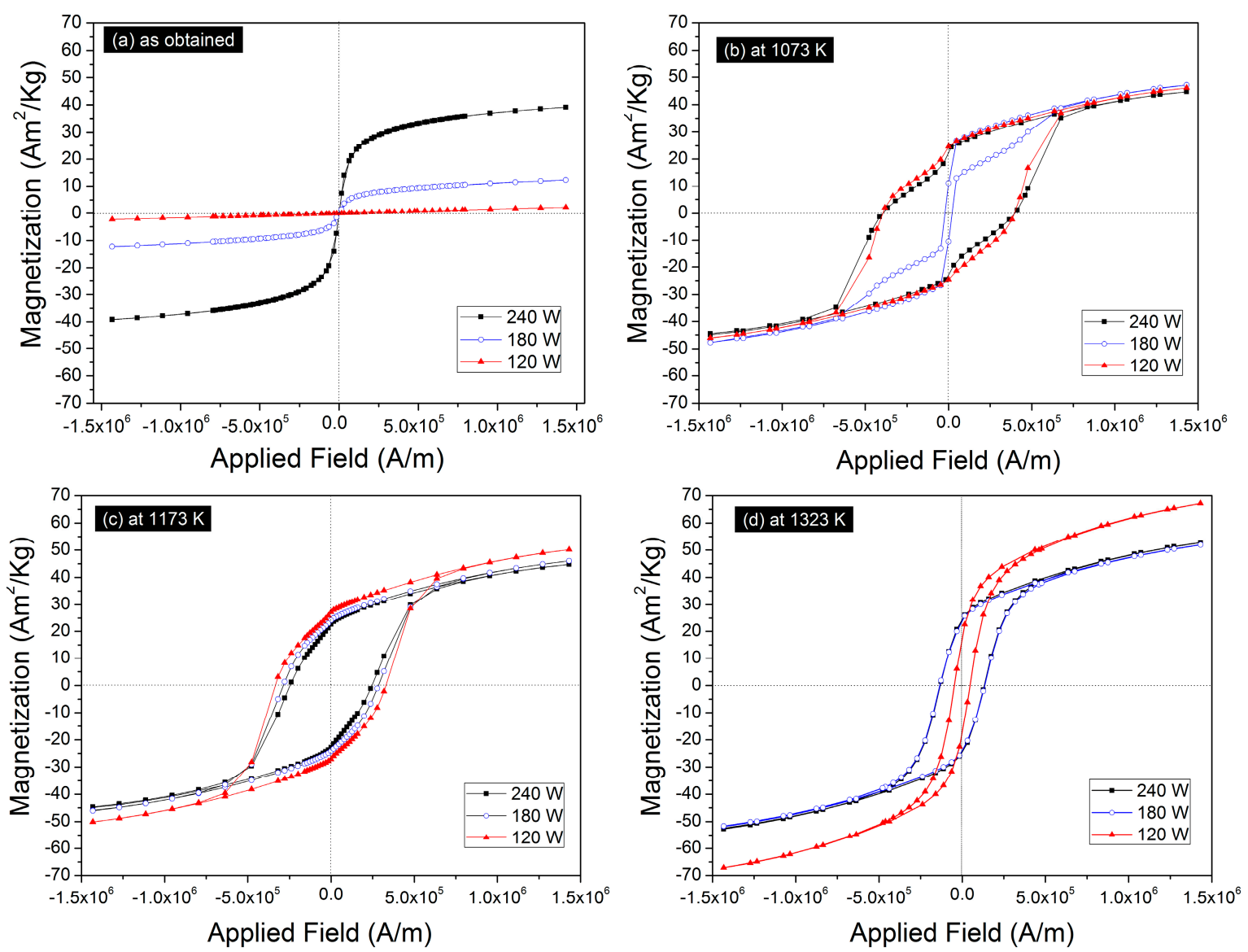

Figure 7. Magnetic hysteresis cycles powders obtained by sonochemistry at 120, 180, and $240 \mathrm{~W}$ of SOP for $3 \mathrm{~h}$. (a) Without annealing; (b) With annealing at $1073 \mathrm{~K}$; (c) With annealing at $1173 \mathrm{~K}$; and (d) With annealing at $1323 \mathrm{~K}$.

Figure $7 \mathrm{~b}$ shows the hysteresis loops $\mathrm{M}(\mathrm{H})$ of the powders obtained by sonochemistry at 120,180 , and $240 \mathrm{~W}$ of SOP, heat treated at $1073 \mathrm{~K}$. As observed, all samples showed ferrimagnetic behavior with high specific magnetization $\left(\sim 46 \mathrm{Am}^{2} / \mathrm{kg}\right.$ in all cases of SOP) and high coercivity (in the case of the powders obtained at 120 and $240 \mathrm{~W}$ ), confirming the presence of $\mathrm{SrFe}_{12} \mathrm{O}_{19}$. All annealed powders showed Perminvar hysteresis loops (also known as "wasp waist"), and were more noticeable in the material synthesized at $180 \mathrm{~W}$, which showed an unexpected low coercivity of $2.31 \times 10^{4} \mathrm{~A} / \mathrm{m}$. These types of hysteresis loops are associated with the antiferromagnetic coupling of hard and soft magnetic phases, in this case, $\mathrm{SrFe}_{12} \mathrm{O}_{19}$ and $\mathrm{SrFeO}_{2.5}$, respectively [29]. These loops are obtained during exposure of an external magnetic field with a very narrow width; when the magnetization is set to zero, the loop width reopens. The main feature of this type of form in the hysteresis loops occurs in the presence of soft magnetic materials and is highly favored by compounds where there is an excess of iron [30].

Increasing the temperature of the heat treatment to 1173 and $1323 \mathrm{~K}$ presented the hysteresis loops $\mathrm{M}(\mathrm{H})$ shown in Figure $7 \mathrm{c}, \mathrm{d}$, respectively. It was observed that all samples showed a change in the hysteresis loops, showing the typical behavior of a hard magnetic phase that corresponded 
to $\mathrm{SrFe}_{12} \mathrm{O}_{19}$, confirming that the reaction for obtaining the hexagonal $\mathrm{SrFe}_{12} \mathrm{O}_{19}$ was completed. The powders obtained from the $1173 \mathrm{~K}$ had a specific magnetization value below the values reported for strontium hexaferrite $[4,13,18]$, this was due to the presence of secondary phases $\left(\mathrm{SrFeO}_{2.5}, \alpha-\mathrm{Fe}_{2} \mathrm{O}_{3}\right.$, $\mathrm{Fe}_{2} \mathrm{O}_{3}$ ) in the strontium hexaferrite that distort the collinear arrangement of parallel spin, therefore, it is known that the value of $\mathrm{Ms}$ in the $\mathrm{SrFe}_{12} \mathrm{O}_{19}$ is determined by the distribution of $\mathrm{Fe}^{3+}$ ions in five different crystallographic sites and by the super exchange interaction between the Fe-O-Fe bond. These cases are similar to the materials obtained at 180 and $240 \mathrm{~W}$ heat treated at $1323 \mathrm{~K}$. The optimal results were shown in those obtained from the powder synthesized at $120 \mathrm{~W}$ of SOP as a significant increase in the specific magnetization was present in the powders obtained at $1173 \mathrm{~K}$ and reached a value of $67.15 \mathrm{Am}^{2} / \mathrm{kg}$ with an $\mathrm{Hc}$ of $4.69 \times 10^{4} \mathrm{~A} / \mathrm{m}$ from the thermal treatment at $1323 \mathrm{~K}$. Additionally, this powder had a decrease in the coercive field, which was due to the small $\mathrm{D}(56.81 \mathrm{~nm})$ confirmed by SEM, where this value was below the critical radius of the hexaferrite $(367.22 \mathrm{~nm})$. This value separates the transition of a monodomain state to a magnetic multidomain [13]. Additionally, it showed behavior belonging to a superparamagnetic material, expected for single-domain nanoparticles. The decrease of the coercive field of mono-domain nanoparticles was strongly related to the crystallite size and can be explained by Herzer's theory [31]. According to this theory, the coercivity of nanoparticles is proportional to $\mathrm{D}^{6}$, when the size is in a single-domain size and is inversely proportional, i.e., $1 / \mathrm{D}$ for multi-domain particles. Table 3 lists the values of the magnetic parameters, specific magnetization $(\mathrm{Ms})$, remanent magnetization $(\mathrm{Mr})$, and coercive field $(\mathrm{Hc})$ obtained from the magnetic analysis at room temperature.

Table 3. Magnetic saturation (Ms), remanent magnetization (Mr), and coercitivity field (Hc) of sonicated powders at 120,180 , and $240 \mathrm{~W}$ of SOP thermal treatments.

\begin{tabular}{|c|c|c|c|c|c|}
\hline SOP (W) & Annealing Temperature (K) & $\operatorname{Ms}\left(\mathrm{Am}^{2} / \mathrm{Kg}\right)$ & $\operatorname{Mr}\left(\mathrm{Am}^{2} / \mathrm{Kg}\right)$ & Hc (A/m) & Mr/Ms (adim) \\
\hline \multirow{3}{*}{120} & 1073 & 46.13 & 24.65 & $3.94 \times 10^{5}$ & 0.53 \\
\hline & 1173 & 52.02 & 28.01 & $3.35 \times 10^{5}$ & 0.53 \\
\hline & 1323 & 67.15 & 17.03 & $4.69 \times 10^{4}$ & 0.25 \\
\hline \multirow{3}{*}{180} & 1073 & 47.71 & 15.23 & $2.31 \times 10^{4}$ & 0.31 \\
\hline & 1173 & 45.60 & 24.72 & $3.03 \times 10^{5}$ & 0.54 \\
\hline & 1323 & 51.71 & 23.93 & $1.36 \times 10^{5}$ & 0.46 \\
\hline \multirow{3}{*}{240} & 1073 & 44.72 & 22.62 & $3.91 \times 10^{5}$ & 0.50 \\
\hline & 1173 & 45.02 & 23.02 & $2.49 \times 10^{5}$ & 0.51 \\
\hline & 1323 & 52.01 & 24.24 & $1.47 \times 10^{5}$ & 0.46 \\
\hline
\end{tabular}

The value of remanent magnetization and the ratio $(\mathrm{Mr} / \mathrm{Ms})$ of the powders obtained at different SOPs, were calculated. This ratio takes values between 0 and 1 , and represents the existence or absence of different types of exchanges of magnetic domains. When $R<0.5$, particles interact through a magnetostatic interaction; when $R=0.5$, it indicates that the particles do not interact, are randomly oriented, and undergo coherent rotations. When $0.5<R<1$, it indicates that there is a strong interaction of change and coupling between the particles [32]. It is well known that the Ms and Mr decrease monotonously and that the coercive field increases or decreases randomly, which is attributed to microstructural characteristics (particle size, morphology, crystallinity, etc.), as well as the homogeneity of the material and the value of the magnetocrystalline anisotropy constant. However, these factors are not decisive when determining the variation of the coercive field, since in the synthesized samples of this work, these values were irregular with increases in SOP. This decrease in the coercive field of this specific case was due to the variation of any of these parameters, or the molar ratio of $\mathrm{Fe}^{3+}$ is much lower than 12 (which would produce vacancies of $\mathrm{Fe}^{3+}$ in the crystal structure of the $\mathrm{SrFe}_{12} \mathrm{O}_{19}$ ), as a result, when the material is subjected to magnetization and the demagnetization process, these ionic vacancies avoid movement of the Bloch walls. The experimental value of the ratio $\mathrm{Mr} / \mathrm{Ms}$ for the powders obtained at $1323 \mathrm{~K}$ heat treatment with 180 and $240 \mathrm{~W}$ was 0.46 , indicating that the 
particles were randomly oriented, while that obtained at $120 \mathrm{~W}$ was 0.25 , indicating that there was magnetostatic interaction, which can be attributed to the particle size obtained.

\section{Conclusions}

This work presented the effects induced by the variation of the SOP applied at 120, 180, and $240 \mathrm{~W}$ in the synthesis of $\mathrm{SrFe}_{12} \mathrm{O}_{19}$ nanoparticles by a sonochemical assisted method of a mixture of metal salts dissolved in a polyol solution composed by DEG: $\mathrm{H}_{2} \mathrm{O}$. The results confirmed a notable influence of the variation in SOP on the crystal structure, size crystal, size particle, morphology, and magnetic properties. Powders "as obtained" from the method of synthesis were identified as a phase of $\mathrm{Fe}_{3} \mathrm{O}_{4}$, which showed an increment of degree of crystallinity with the increase in the SOP applied; this phase, along with another phase identified as $\mathrm{SrCO}_{3}$, induced the synthesis of strontium hexaferrite after the mixture was subject to 1073,1173 , and $1323 \mathrm{~K}$ of heat treatment in air. The powders obtained at higher SOPs $(180$ and $240 \mathrm{~W})$ had a higher rate of impurities in their composition due to an excess of $\mathrm{Fe}^{3+}$, such as $\alpha-\mathrm{Fe}_{2} \mathrm{O}_{3}, \mathrm{FeO}$, and the Perovskite $\mathrm{SrFeO}_{2.5}$; this last phase being obtained in the powders at $1073 \mathrm{~K}$ was the main cause of the formation of a hysteresis loop known as "wasp waist". The heat treatment at $1173 \mathrm{~K}$ indicated the complete formation of strontium hexaferrite, and at $1323 \mathrm{~K}$, a simple-phase was obtained. The magnetic properties of the particles of $\mathrm{SrFe}_{12} \mathrm{O}_{19}$ obtained at $120 \mathrm{~W}$ of SOP at $1323 \mathrm{~K}$ showed a high specific magnetization of $67.15 \mathrm{Am}^{2} / \mathrm{kg}$ at $1.43 \times 10^{6} \mathrm{~A} / \mathrm{m}$, and coercivity of $4.69 \times 10^{4} \mathrm{~A} / \mathrm{m}$. Moreover, it had an average size of $56.81 \mathrm{~nm}$, which indicated superparamagnetic behavior and showed a spherical morphology, which was confirmed by SEM. Therefore, a conclusion was reached where the effects of increases in SOP of the powders obtained from the process of synthesis produced a greater percentage in volume of the $\mathrm{Fe}_{3} \mathrm{O}_{4}$ phase, promoted a high degree of crystallinity, and decreased in the crystal size. Furthermore, it produced a crystallization of secondary phases in the powders obtained at 120,180, and $240 \mathrm{~W}$ when heat treated. Using high SOPs (180 and $240 \mathrm{~W}$ ) promoted an agglomeration of the obtained particles and a modification in its morphology. The magnetic properties were affected by the impurities present in the powders, which had a direct effect on the magnetic interactions of the material, resulting in significant changes in the magnetic properties of the hexaferrite strontium nanoparticles obtained. It can be concluded, in accordance with the results discussed above, that it is convenient to use a SOP of $120 \mathrm{~W}$ for the synthesis of a simple-phase of $\mathrm{SrFe}_{12} \mathrm{O}_{19}$ that is free of secondary phases with remarkable magnetic properties.

Acknowledgments: The authors thank the Center of Nanosciences and Micro and Nanotechnology of the National Polytechnic Institute, in particular Hugo Martínez Gutiérrez, for morphological characterization.

Author Contributions: Roberto L. Palomino Resendiz performed the experiments, discussed the experimental data, and wrote the paper. Félix Sánchez De Jesús performed the magnetic characterization and discussed the experimental data. Ana M. Bolarín Miró and Claudia A. Cortés Escobedo designed the experiments and discussed the experimental data. Leticia E. Hernández Cruz reviewed the manuscript.

Conflicts of Interest: The authors declare no conflict of interest.

\section{References}

1. Chong, S.V.; Williams, G.V.M.; Kennedy, J.; Fang, F.; Tallon, J.L.; Kadowaki, K. Large low-temperature magnetoresistance in $\mathrm{SrFe}_{2} \mathrm{As}_{2}$ single crystals. EPL Europhys. Lett. 2013, 104, 17002. [CrossRef]

2. Töpfer, J.; Seifert, D.; Le Breton, J.-M.; Langenhorts, F.; Chlan, V.; Kouril, K.; Stepánková, H. Hexagonal ferrites of X-, W-, and M-type in the system Sr-Fe-O: A comparative study. J. Solid State Chem. 2015, 226, 133-141. [CrossRef]

3. Fang, C.M.; Kools, F.; Metselar, R.; de With, G.; de Groot, R.A. Magnetic and electronic propieties of strontium hexaferrite $\mathrm{SrFe}_{12} \mathrm{O}_{19}$ from first-principles calculations. J. Phys. Condens. Matter 2003, 15, 6229-6237. [CrossRef]

4. Zi, Z.F.; Sun, Y.P.; Zhu, X.B.; Yang, Z.R.; Dai, J.M.; Song, W.H. Structural and magnetic properties of $\mathrm{SrFe}_{12} \mathrm{O}_{19}$ hexaferrite synthetized by a modified chemical co-precipitation method. J. Magn. Magn. Mater. 2008, 320, 2746-2751. [CrossRef] 
5. Xia, A.; Zuo, C.; Chen, L.; Jin, C.; Lv, Y. Hexagonal $\mathrm{SrFe}_{12} \mathrm{O}_{19}$ ferrites: Hydrothermal synthesis and their properties. J. Magn. Magn. Mater. 2013, 332, 186-191. [CrossRef]

6. Kostishyn, V.G.; Panina, L.V.; Kozhitov, L.V.; Timofeev, A.V.; Kovalev, A.N. Synthesis and multiferroic properties of M-type $\mathrm{SrFe}_{12} \mathrm{O}_{19}$ hexaferrite ceramics. J. Alloys Compd. 2015, 645, 297-300. [CrossRef]

7. Bolarín-Miró, A.M.; Sánchez-De Jesús, F.; Cortés-Escobedo, C.A.; Díaz-De la Torre, S.; Valenzuela, R. Synthesis of M-type $\mathrm{SrFe}_{12} \mathrm{O}_{19}$ by mechanosynthesis assisted by spark plasma sintering. J. Alloys Compd. 2015, 643, S226-S230. [CrossRef]

8. Ganjali, M.; Ganjali, M.; Eskandari, A.; Aminzare, M. Effect of Heat Treatment on Structural and Magnetic Properties of Nanocrystalline $\mathrm{SrFe}_{12} \mathrm{O}_{19}$ Hexaferrite Synthesized by Co-Precipitation Method. J. Adv. Mater. Process. 2013, 4, 41-48. [CrossRef]

9. Singhal, S.; Namgyal, T.; Singh, J.; Chandra, K.; Bansal, S. A comparative study on the magnetic properties of $\mathrm{MFe}_{12} \mathrm{O}_{19}$ and $\mathrm{MAlFe}_{11} \mathrm{O}_{19}(\mathrm{M}=\mathrm{Sr}, \mathrm{Ba}$ and $\mathrm{Pb})$ hexafererites with different morphologies. Ceram. Int. 2011, 37, 1833-1837. [CrossRef]

10. Rashid, A.U.; Southern, P.; Darr, J.A.; Awan, S.; Manzoor, S. Strontium hexaferrite $\left(\mathrm{SrFe}_{12} \mathrm{O}_{19}\right)$ based composites for hypertermia applications. J. Magn. Magn. Mater. 2013, 344, 134-139. [CrossRef]

11. Choudhury, H.A.; Choudhary, A.; Sivakumar, M.; Moholkar, V.S. Mechanistic investigation of the sonochemical synthesis of zinc ferrite. Ultrason. Sonochem. 2013, 20, 294-302. [CrossRef] [PubMed]

12. Dang, T.M.H.; Trinh, V.D.; Bui, D.H.; Phan, M.H.; Huynh, D.G. Sol-gel hydrothermal synthesis of strontium hexaferrite nanoparticles and relation between their crystal structure and high coercivity properties. Adv. Nat. Sci. Nanosci. Nanotechnol. 2012, 3, 025015. [CrossRef]

13. Tenorio Gonzalez, F.N.; Bolarín Miró, A.M.; Sánchez De Jesús, F.; Cortés Escobedo, C.A. Mechanism and microstructural evolution of polyol mediated synthesis of nanostructure M-type $\mathrm{SrFe}_{12} \mathrm{O}_{19}$. J. Magn. Magn. Mater. 2016, 407, 188-194. [CrossRef]

14. Hessien, M.M.; Rashad, M.M.; El-Barawy, K. Controlling the composition properties of strontium hexaferrite synthetized by co-precipitation method. J. Magn. Magn. Mater. 2008, 320, 336-343. [CrossRef]

15. Viet Nga, T.T.; Duong, N.P.; Loan, T.T.; Hien, T.D. Key step in the synthesis of ultrafine strontium ferrite powders $\left(\mathrm{SrFe}_{12} \mathrm{O}_{19}\right)$ by sol-gel method. J. Alloys Compd. 2014, 610, 630-634. [CrossRef]

16. Kandjani, A.E.; Tabriz, M.F.; Pourabbas, B. Sonochemical synthesis of ZnO nanoparticles: The effect of temperature and sonocation power. Mater. Res. Bull. 2008, 43, 645-654. [CrossRef]

17. Ohayon, E.; Gedanken, A. The application of ultrasound radiation to the synthesis of nanocystalline metal oxide in a non-aqueous solvent. Ultrason. Sonochem. 2010, 17, 173-178. [CrossRef] [PubMed]

18. Palomino, R.L.; Bolarín Miró, A.M.; Tenorio, F.N.; Sánchez De Jesús, F.; Cortés Escobedo, C.A.; Ammar, S. Sonochemical assisted synthesis of $\mathrm{SrFe}_{12} \mathrm{O}_{19}$ nanoparticles. Ultrason. Sonochem. 2016, 29, 470-475. [CrossRef] [PubMed]

19. Kaviyarasu, K.; Geetha, N.; Kanimozhi, K.; María Magdalane, C.; Sivaranjani, S.; Ayeshamariam, A.; Keneddy, J.; Maaza, M. In vitro citotoxicity effect and antibacterial performance of human lung epothelial cells A549 activity of Zinc oxide doped $\mathrm{TiO}_{2}$ nanocrystals: Investigation of bio-medical application by chemical method. Mater. Sci. Eng. C 2017, 74, 325-333. [CrossRef] [PubMed]

20. Kaviyarasu, K.; Magdalane, C.M.; Kanimozhi, K.; Kennedy, J.; Siddhardha, B.; Reddy, E.S.; Rotte, N.K.; Sharma, C.S.; Thema, F.T.; Letsholathebe, D.; et al. Elucidation of photocatalysis, photoluminicense and antibacterial studies of $\mathrm{ZnO}$ thin films by spin coating method. J. Photochem. Photobiol. B 2017, 173, 466-475. [CrossRef] [PubMed]

21. Hassanjani-Roshan, A.; Vaezi, M.R.; Shokuhfar, A.; Rajabali, Z. Synthesis of iron oxide nanoparticles via sonochemical method and their characterization. Particuology 2011, 9, 95-99. [CrossRef]

22. Lutterotti, L.; Matthies, S.; Wenk, H.R. MAUD: A Friendly Program for Material Analysis Using Diffraction. IUCr Newsl. CPD 1999, 21, 14-15.

23. COD, Crystallography Open Database. Available online: http://www.crystallography.net/cod/search.html (accessed on 17 January 2018).

24. Israr, F.; Kim, D.K.; Kim, Y.; Oh, S.J.; Ng, K.C.; Chun, W. Synthesis of porous Cu-BTC with ultrasonic treatment: Effects of ultrasonic power and solvent condition. Ultrason. Sonochem. 2016, 29, 186-193. [CrossRef] [PubMed]

25. Bailey, A.V.; Honold, E.; Skau, E.L. Topochemical mechanims involved in the preparation and deacetylation of partially acetylated cottons. Text. Res. J. 1958, 28, 861-873. [CrossRef] 
26. Nemury, A.; Weiss, M.; Gainetdinov, I.; Boldyrev, V.; Schöllhorn, R. Room temperature electrochemical redox reactions of the defect Perovskite $\mathrm{SrFeO}_{2.5-\mathrm{x}}$. Chem. Mater. 1998, 10, 2403-2411. [CrossRef]

27. Zhao, B.; Wang, Y.; Guo, H.; Wang, J.; He, Y.; Jiao, Z.; Wu, M. Iron oxide (III) nanoparticles fabricated by electron beam irradiation method. Mater. Sci. 2007, 25, 1143-1148.

28. Hazen, R.M.; Jeanloz, R. Wustite $\left(\mathrm{Fe}_{1-x} \mathrm{O}\right)$ : A review of its defect structure and physical properties. Rev. Geophys. Spa Phys. 1984, 22, 37-46. [CrossRef]

29. Bennett, L.H.; Torre, E.D. Analysis of wasp-waist hysteresis loops. J. Appl. Phys. 2005, 97, 10E502. [CrossRef]

30. Eckert, O. Ferrites with constricted loops and thermal magnetic treatment. Proc. IEEE 1956, 104, 428-432. [CrossRef]

31. Herzer, G. Grain size dependence of coercivity and permeability in nanocrystalline ferromagnets. IEEE Trans. Magn. 1990, 26, 1397-1402. [CrossRef]

32. Xu, Y.F.; Ma, Y.Q.; Xu, S.T.; Zan, F.L.; Zheng, G.H.; Dai, Z.X. Effects of vacancy and exchange-coupling between grains on magnetic properties of $\mathrm{SrFe}_{12} \mathrm{O}_{19}$ and $\alpha-\mathrm{Fe}_{2} \mathrm{O}_{3}$ composites. Mater. Res. Bull. 2014, 57, 13-18. [CrossRef]

(C) 2018 by the authors. Licensee MDPI, Basel, Switzerland. This article is an open access article distributed under the terms and conditions of the Creative Commons Attribution (CC BY) license (http:/ / creativecommons.org/licenses/by/4.0/). 